\title{
DO DIAGNÓSTICO À MATERIALIZAÇÃO: o design como fator estratégico, gerando competitividade e diferenciação às empresas
}

\author{
Marina Cuneo Aguiar \\ Universidade Federal de Santa Catarina \\ marina.c.aguiar@gmail.com \\ Eugenio Andrés Díaz Merino \\ Universidade Federal de Santa Catarina \\ eugenio.merino@ufsc.br \\ Giselle Schmidt Alves Díaz Merino \\ Universidade Federal de Santa Catarina \\ gisellemerino@gmail.com \\ Bruna Pasquali Plentz \\ Universidade Federal de Santa Catarina \\ bruplentz@gmail.com \\ Giovanni Luigi Piazza \\ Universidade Federal de Santa Catarina \\ gio.piazza@gmail.com
}

\begin{abstract}
Resumo: O design em uma organização traz diferenciação perante seus concorrentes, sendo um fator de identificação e valorização para o públicoalvo. Este artigo visa verificar o impacto do processo de design como fator estratégico, gerando competitividade e diferenciação às empresas. Buscase também levantar seus conceitos e ferramentas para seu desenvolvimento por meio de revisão bibliográfica, além da aplicação prática da gestão de design em uma situação real. No que diz respeito à metodologia, utilizou-se o GODP - Guia de Orientação para o Desenvolvimento de Produtos, a ferramenta PDCA e o modelo de avaliação organizacional CDS. A aplicação do modelo CDS evidenciou os pontos fortes e de melhoria da organização em relação aos indicadores de inovação, mercado, preço, comunicação, qualidade do serviço, infraestrutura e sustentabilidade ambiental, social e econômica. A ferramenta PDCA possibilitou a organização e o gerenciamento do projeto no que diz respeito ao planejamento e operacionalização das ações do plano estratégico. Dentre as ações operacionais foram desenvolvidas a identidade visual, materiais de papelaria, bonés e camisetas da escola de esportes.
\end{abstract}


Palavras-chave: design, gestão de design, competitividade, diferenciação, sustentabilidade.

\begin{abstract}
The Design in an organization brings differentiation to its competitors, becoming a factor of identification and appreciation for the costumers. This article aims to verify the impact of the design as a strategic factor, bringing competitiveness and differentiation to companies. concepts and tools are also addressed with literature review, besides the practical application of design management in a real situation. About methodology, it was used GODP - Guide for Developing Products, the PDCA tool and organizational assessment model CDS. The CDS application revealed the strengths and improvement points of the organization in relation to indicators of innovation, market, price, communication, quality of service, infrastructure and environmental, social and economic sustainability. PDCA allowed the project organization and its management with regard to planning and implementing the strategic plan of actions. About operational actions were developed the branding, graphic materials, caps and $t$-shirts sports school materials. For its preparation, was realized a literature review and a practical application of design management in a real situation. The procedures were based on the Guidance for Product Development, the tool PDCA and the model of organizational assessment CDS.
\end{abstract}

Key-words: design, design management, competitiveness, differentiation, sustainability.

\title{
1. INTRODUÇÃO
}

O design visto de modo estratégico contribui para a cultura organizacional das empresas, buscando oportunidades de inovação e auxiliando na resolução de problemas, dando base para o processo de formulação de suas estratégias (MOZOTA, 2011). De que modo, porém, a gestão de design pode contribuir efetivamente para o aumento da competitividade nas empresas e na diferenciação de mercado?

Esta pesquisa tem como objetivo geral verificar o impacto do processo de design como fator estratégico, gerando competitividade e diferenciação às empresas. Busca-se também levantar seus conceitos, técnicas e ferramentas para seu desenvolvimento, bem como sua aplicação em um projeto prático, aplicado em uma empresa (Pinheiro Escola de Esportes) localizada em Florianópolis, Santa Catarina. A pesquisa encontra-se composta por duas etapas: a primeira diz respeito à parte teórica e uma segunda etapa prática. Classifica-se como aplicada quanto sua natureza, qualitativa quanto a sua forma de abordagem, exploratório-descritiva em relação a seus objetivos, e do ponto de vista dos procedimentos técnicos enquadra-se como estudo de caso. Para sua elaboração, inicialmente realizou-se uma revisão bibliográfica dos principais conceitos relacionados ao tema; em seguida, o estudo e o desenvolvimento do projeto teórico-prático de gestão de design. Os procedimentos adotados tiveram como base a metodologia projetual GODP - Guia de Orientação para o Desenvolvimento de Produtos, a ferramenta de gestão PDCA (Plan, Do, Check, Act) e a ferramenta de análise CDS - Competitividade, Diferenciação e Sustentabilidade. O 
modelo CDS tem sua base conceitual no processo de Gestão de Design e visa a diagnosticar o estágio dos diferentes indicadores que configuram cada uma das dimensões de análise. O modelo também será utilizado como ferramenta de apoio estratégica.

\section{BASE TEÓRICA}

\subsection{Design}

Nos mercados globalizados o design funciona como critério de qualidade e identidade (WOLF, 1998). Mozota (2011) considera o processo de design como um processo de identidade, pois define a organização, seus clientes e seus investidores, diferenciando-a de seus concorrentes, oferecendo um identificador-chave para 0 público. Desta forma, o design é visto como uma ferramenta que proporciona um diferencial competitivo às organizações, o que é corroborado pela definição do AIGA American Institute Of Graphic Arts (2014):

\footnotetext{
Design é um investimento no pensamento inovador, no posicionamento, na gestão de marca e na comunicação que cria valor para os negócios em termos de vantagens competitivas, confiança e lealdade pelos consumidores e fatia de mercado. Num mercado global e local em constantes mudanças, o pensamento do designer auxilia os negócios a enfrentarem a complexidade das condições com soluções criativas.
}

O design abrange diferentes áreas de atuação e especificidades, dentre as quais se utiliza para esta pesquisa o design aplicado à gestão de design.

\subsection{Design, estratégia e gestão nas empresas}

O design clássico, focado no operacional, vem sendo complementado com uma visão contemporânea denominada estratégica, de modo a integrar os aspectos do fazer design, com o pensar design. Esta nova visão vem sendo largamente difundida e implementada na gestão das empresas, sendo fator de diferenciação.

Gillespie (2002, p.02) faz uma relação entre esses três termos: design, estratégia e gestão, interligando-os e formando um conceito central, "strategic design management" (SDM) que para o autor é "um processo de negócios que incorpora o design e sua gestão no processo de formação da estratégia, e implementado em todos os níveis da organização".

Segundo Gimeno (2000) estratégia empresarial é uma previsão de como a empresa atinge seus objetivos em função dos recursos disponíveis e as características do ambiente em que atua. A estratégia não deve ser um processo gerencial isolado; mas sim "uma das etapas de um processo contínuo lógico que movimenta toda a organização desde a declaração de missão de alto nível até o trabalho executado pelos empregados de linha de frente e de suporte" (KAPLAN e NORTON, 2004, p. 34). Neste sentido, a gestão tem sua contribuição no gerenciamento desse processo.

Para Ferreira (2004), gestão é o ato de gerir, refere-se à gerência, administração; gestão de negócios. Martins e Merino (2011) corroboram com essa 
questão, afirmando que a "gestão ou administração é a condução racional das atividades de uma organização, sendo imprescindível para sua existência, sobrevivência e sucesso".

De acordo com Mozota (2011), o nível estratégico da gestão design consiste em gerir a contribuição do design para o processo de formulação da estratégia. O DMI Design Management Institute (2014) apresenta uma definição para a gestão de design:

\begin{abstract}
[...] é o aspecto organizacional do Design. A gestão de design abrange os processos em curso, as decisões de negócios e as estratégias que permitem a inovação e a criação de produtos, serviços, comunicações, ambientes e marcas bem projetados, as quais melhoram a qualidade de vida e proporcionam o sucesso organizacional. Aprofundando-se na definição, a gestão de design busca unir o design, a inovação, a tecnologia, a administração e os consumidores para promover uma vantagem competitiva por meio dos três fatores base: econômico, social / cultural e ambiental.
\end{abstract}

O Design Council (2014) aponta alguns benefícios para as empresas que aplicam a gestão de design: é importante, pois define alvos e metas; mostra que o design é um processo a ser envolvido em mais do que simplesmente um pedido de produto; promove design como um serviço profissional que os negócios empregam, assim como em consultorias de negócios, agências de marketing ou assessorias jurídicas. No entanto, para que se obtenha sucesso com a aplicação da gestão de design, esta deve ser incorporada em todo processo, envolvendo assim todos os níveis da organização e tornando-se uma questão estratégica.

\title{
2.4 Metodologia
}

Para desenvolvimento do projeto, utilizou-se a metodologia GODP (Guia de Orientação para o Desenvolvimento de Produtos), desenvolvida pelo Núcleo de Gestão de Design da UFSC - NGD/UFSC. O GODP tem por objetivo organizar e oferecer uma sequência de ações que permitam com que o design seja concebido de forma consciente, considerando o maior número de aspectos e respondendo de forma mais assertiva e consistente aos objetivos fixados para a prática projetual (MERINO, 2013).

Vale destacar que durante o processo de desenvolvimento do projeto foram realizados encontros e cada etapa contou com a participação do cliente, em um processo participativo, havendo constantes feedbacks e trocas de informações entre o parceiro e a equipe responsável.

O GODP apresenta como elementos estruturais do processo de gestão de design a inovação constante dos produtos, juntamente com uma integração eficaz de todas as áreas envolvidas, utilizando-se de um modelo de gestão participativa que valoriza todos os envolvidos no processo (MERINO, 2002). Essa proposta apoia-se nos fundamentos que diferenciam o design operacional do estratégico, como componentes do processo, porém complementares (MOZOTA, 2011). O percurso proposto pelo GODP se utiliza de modelos, sendo o primeiro o Modelo CDS, configurado por três pontos chaves denominados dimensões (competitividade, diferenciação e sustentabilidade), tendo como finalidade a valorização e aferição do 
estágio do produto (MERINO, 2010). As três dimensões - Competitividade, Diferenciação e Sustentabilidade - funcionam como pontos-chave do modelo e auxiliam no diagnóstico sobre a situação que se encontra o produto, produtores e produção, em diferentes etapas de desenvolvimento do projeto, em soma configura-se como uma análise organizacional.
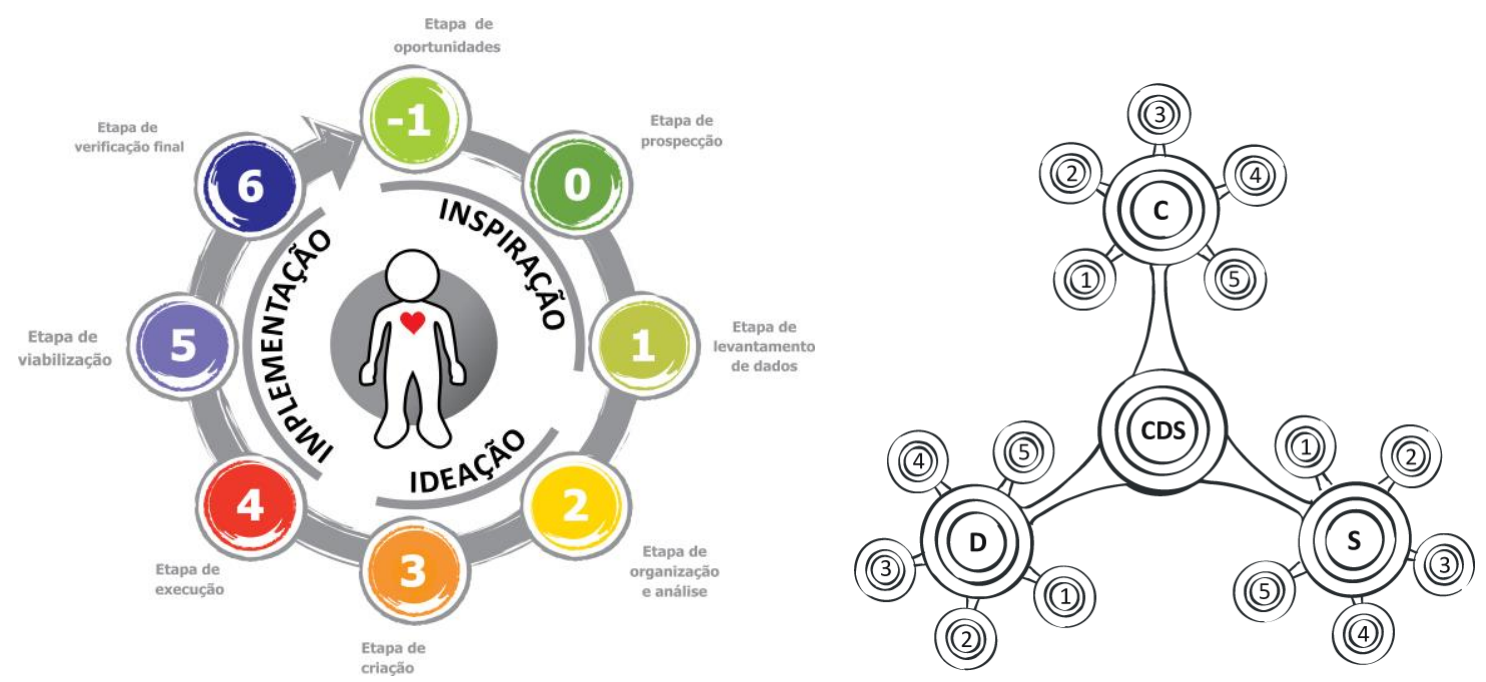

Figura 1 - Metodologia GODP e Modelo CDS, respectivamente.

Fonte: Merino (2013), Merino (2010).

O diagnóstico contém indicadores que são pré-estabelecidos. Desta maneira, deve-se anteriormente à aplicação do modelo definir o número e tipo de indicadores a partir dos levantamentos e análises realizados junto à organização. Recomenda-se a utilização do mesmo número de indicadores para todas as dimensões para que estas sejam estabelecidas com médias formadas pela mesma quantidade (TEIXEIRA, 2011).

\subsubsection{PDCA}

PDCA (Plan, Do, Check, Act) é a sigla que denomina o Método de Melhorias (Souza, 1997), trata-se de um ciclo de controle estatístico do processo ou problema. Nesta pesquisa, o PDCA foi utilizado como ferramenta de gerenciamento do projeto.

Segundo Ferreira (2004), a palavra "planejar" (plan) refere-se a fazer o plano ou planta de; projetar, fazer o planejamento de algo; elaborar um plano ou roteiro, programar. "Fazer" (do) significa dar existência ou forma a; produzir física ou moralmente; criar. "Verificar" (check) diz respeito a provar a verdade; investigar a verdade; comprovar a exatidão de, confirmar, corroborar. E "agir" (act) seria praticar ou efetuar na qualidade de agente; obrar, operar, atuar. Para Carbellido e Manuel (2005), o módulo Plan corresponde à etapa de visualização de onde se quer chegar. Desta forma, em um primeiro instante é realizado um diagnóstico para saber a situação atual da organização, teorias são desenvolvidas a respeito das possíveis soluções e, finalmente, estipula-se um plano de ação. No módulo Do, o plano de ação é colocado em prática, em paralelo com algum plano de controle para certificar seu correto andamento. $\mathrm{O}$ módulo Check identifica os efeitos e problemas gerados durante o processo, bem como avalia os efeitos e incorpora os resultados. O módulo Act 
conclui o ciclo da qualidade, os resultados são estudados, as mudanças são confirmadas e são desencadeadas as melhorias.

\section{DESENVOLVIMENTO E RESULTADOS}

O projeto foi desenvolvido para o Pinheiro Esportes, uma escola que oferece aulas de modalidades esportivas diversas, como tênis, pilates, futebol e futsal, localizado na cidade de Florianópolis, Santa Catarina. Inicialmente foi apresentada como demanda a reformulação da identidade visual da empresa e padronização de suas aplicações conforme a nova proposta de identidade visual. Ao longo do projeto e das etapas da metodologia, puderam ser identificadas outras demandas a serem supridas por meio de estratégias de design, sendo implementadas juntamente à organização. Com base em Merino (2013), são apresentadas a seguir de forma simplificada as etapas do GODP.

\subsubsection{Etapas -1 e 0: Oportunidade e Prospecção/solicitação}

Estas etapas, - 1 e 0 , referem-se às fases de Oportunidade e Prospecção. A etapa de Oportunidade é aquela na qual são verificadas as oportunidades do mercado conforme o produto a ser avaliado, considerando um panorama nacional e internacional e a atuação na economia. Desta forma, são evidenciadas as necessidades de crescimento do setor e outras conforme o produto. Na fase de Prospecção é definida a demanda/problemática central que norteará o projeto, realizada após a etapa de Oportunidade. Por ser uma microempresa, o Pinheiro Esportes foi escolhido por ter-se percebido a oportunidade de aplicação da gestão de design como fator de diferenciação e competitividade, e do interesse demonstrado pelo dono da escola, permitindo a intervenção da gestão de design como ferramenta estratégica.

\subsubsection{Etapa 1: Levantamento de dados}

A etapa 1 do GODP foi realizada com base em entrevistas com o proprietário da empresa, além de pesquisas na internet, visitas ao local e estudo de similares e concorrentes, sendo elaborado o briefing de forma a registrar esses dados. Fundado em 2002, o Pinheiro Escola de Esportes estava sediado na AABB - Associação Atlética do Banco do Brasil, no bairro de Coqueiros, na cidade de Florianópolis/SC. Em 2009, a escola foi para o clube Paula Ramos, localizada no bairro Trindade, tendo a possibilidade de oferecer novas atividades, como o pilates, o futebol e o futsal. Atualmente possui uma identidade visual, sendo esta aplicada no site, cartão de visita, ficha de cadastro, papel timbrado, cartaz e alguns anúncios das três modalidades oferecidas. As aplicações da identidade visual verificadas apresentaram falta de padronização, sendo o símbolo modificado sem um padrão aparente em suas diferentes apresentações.

\section{PINHEIRO ESCOLA DE ESPORTES}

Figura 2 - Marca e site do Pinheiro Esportes.

Fonte: Pinheiro Esportes (2012). 
A modalidade tênis destaca-se com carro-chefe da empresa. O número total de alunos da escola é de 212, divididos nas quatro modalidades. O perfil dos alunos é variado no que diz respeito ao sexo e à faixa etária, porém nota-se uma similaridade do perfil econômico, sendo em sua grande maioria pessoas com poder aquisitivo médio alto (classe A/B). Com o estudo feito focando em empresas similares e concorrentes, pode-se verificar um limitado número de escolas oferecendo diversas modalidades esportivas, configurando este um critério de diferenciação de serviço do Pinheiro Esportes.

\subsubsection{Etapa 2: Organização e análise dos dados}

Após o levantamento das informações, estas foram organizadas e analisadas. A Análise SWOT, foi usada de modo a identificar fatores internos (forças e fraquezas) e externos (oportunidades e ameaças) da organização, possibilitando uma análise ambiental desta (FERREL, HARTILINE, 2000). Por meio dela são identificados fatores que podem ter ou não ter impacto na organização, seja de dentro ou de fora, obtendo uma resposta apropriada a ser desenvolvida (BEST, 2006).

De acordo com as informações obtidas, uma pré-análise utilizando o modelo CDS foi realizada (Figura 3), de modo a obter uma análise a respeito da percepção da situação atual da empresa, sendo levados em consideração os itens que se aplicam neste caso. Na competitividade foram analisados os indicadores (1) preço, (2) inovação e (3) mercado. Na diferenciação foram considerados os indicadores (1) comunicação, (2) qualidade no serviço e (3) infraestrutura. E na sustentabilidade, aspectos (1) sociais, (2) ambientais e (3) econômicos.

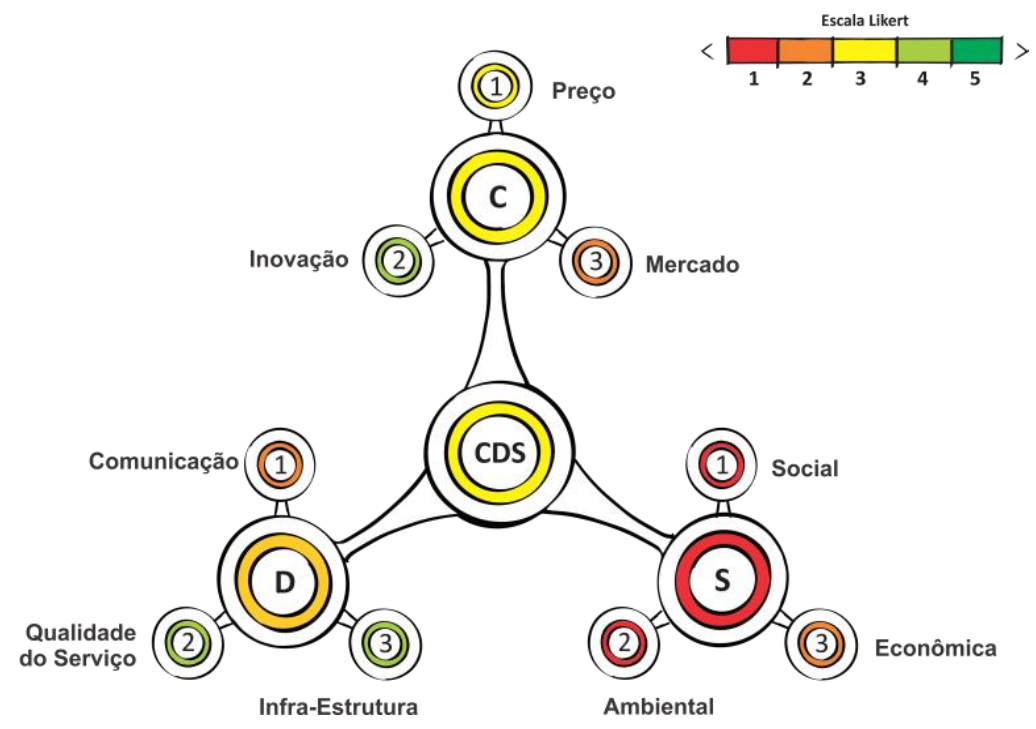

Figura 3 - Modelo CDS: Análise preliminar.

Fonte: Elaborado pelo autor, com base na pesquisa realizada.

A respeito da dimensão Competitividade, a inovação em relação ao serviço prestado mostra-se uma potencialidade a respeito da gama de atividades oferecidas, visto que a maior parte das escolas de esporte se concentra em poucas atividades ou atividades similares (por exemplo, oferece-se futebol de campo e também futsal). Em 
relação ao fato do serviço ser terceirizado por um clube, praticamente não há inovação, sendo que outros clubes na própria cidade também o fazem. De acordo com o observado na pré-análise, a questão de preço apresenta-se regular, não estando nem muito acima ou abaixo da média do mercado. Em relação ao mercado observa-se que as oportunidades de crescimento futuras são promissoras, no entanto a escola de esportes ainda está iniciando, está se estruturando no mercado, o que configura uma fragilidade a ser trabalhada. Em Diferenciação, a qualidade na infraestrutura apresenta-se como uma potencialidade, com campos, quadras e sala bem equipados e em bom estado. A qualidade no serviço também se apresenta como uma potencialidade, tendo diferentes atividades oferecidas com uma boa equipe de profissionais. A comunicação apresenta-se frágil, limitando-se ao site em fase de finalização, folders e cartazes sem um padrão visual. Nas questões relacionadas à Sustentabilidade social e ambiental não foram identificadas ações nesse sentido. Do ponto de vista da sustentabilidade econômica, na questão do empreendimento ser autossustentável financeiramente, percebe-se que ainda está em fase inicial, conforme o quesito mercado, não havendo ainda completa estabilidade, identificando nestes indicadores importantes oportunidades de melhoria.

Neste projeto o PDCA foi utilizado como ferramenta de gerenciamento do plano estratégico, sendo realizadas as duas primeiras etapas de seu ciclo: planejamento (plan) e ação (do). O Modelo CDS e a análise SWOT serviram como embasamento para o desenvolvimento do plano estratégico, devido ao fato de terem permitido a compreensão o contexto no qual o Pinheiro Esportes está inserido. Sendo assim, o plano estratégico foi iniciado tendo como objetivo a elaboração de estratégias coerentes com os objetivos da empresa.

Para elaboração do plano estratégico a empresa deve examinar seu entorno, o ambiente em no qual está inserida e sua estrutura interna, avaliando seus pontos fortes e fracos. Ao analisar a empresa como um todo, é possível prever medidas que permitirão aproveitar suas vantagens e fazer com que seus pontos fracos sejam amenizados, a fim de torná-los a favor da empresa, deixando de ser uma desvantagem (GIMENO, 2000). Como meio de alinhar a organização estrategicamente por meio do design, foram desenvolvidas estratégias, de forma a traçar um caminho a ser percorrido. Essas estratégias foram dividias em objetivos, iniciativas e ações. Objetivos podem ser entendidos como situações futuras que a organização como um todo pretende atingir, por meio deles são estabelecidas linhas-mestras para as atividades da organização (ANDRADE, AMBONI, 2007). As iniciativas estão inseridas dentro dos objetivos, e por sua vez as ações fazem parte das iniciativas. Deste modo, foi elaborado um planejamento para a empresa, levantando seus objetivos de longo prazo, subdividindo-os em iniciativas que deveriam ser tomadas para atingi-los, que por sua vez configuraram ações pontuais a serem executadas pela equipe do projeto ou pela própria empresa ao longo do tempo. Este artigo se delimita as ações desenvolvidas pesquisa até o presente momento.

\subsubsection{Etapa 3: Criação}

A partir das estratégias do projeto são definidos seus conceitos globais, sendo geradas as alternativas preliminares. Estas são submetidas a uma nova análise utilizando-se de técnicas e ferramentas, permitindo a escolha daquelas que 
respondem de melhor forma às especificações de projeto e atendimento dos objetivos. Tendo como base os objetivos, as iniciativas e as ações definidos, além da essência da empresa definida pelo proprietário "levar através do esporte e da atividade física saúde, qualidade de vida e lazer para as pessoas que nos procuram", iniciou-se a etapa 3 referente à criação. Em um primeiro momento foi feita a análise da identidade visual, onde se percebeu uma inconsistência das aplicações, com variações nas formas e nas cores. Além desta análise, também foram levantadas e estudadas identidades visuais de similares e concorrentes (Figura 4). Em linhas gerais, a maioria traz a ideia de movimento, conceito diretamente relacionado ao esporte. Tipografias mais orgânicas e cores verde e azul também são recorrentes em variados tipos de esportes. Por meio de entrevistas e levantamento de dados sobre a empresa, pôde-se definir quatro conceitos básicos, sendo eles: Energia, Bem Estar, Qualidade e Diversidade. Partindo destes conceitos, foi elaborado um painel semântico utilizando imagens que transmitissem esses conceitos e servindo como fonte de inspiração para auxiliar no desenvolvimento das alternativas.

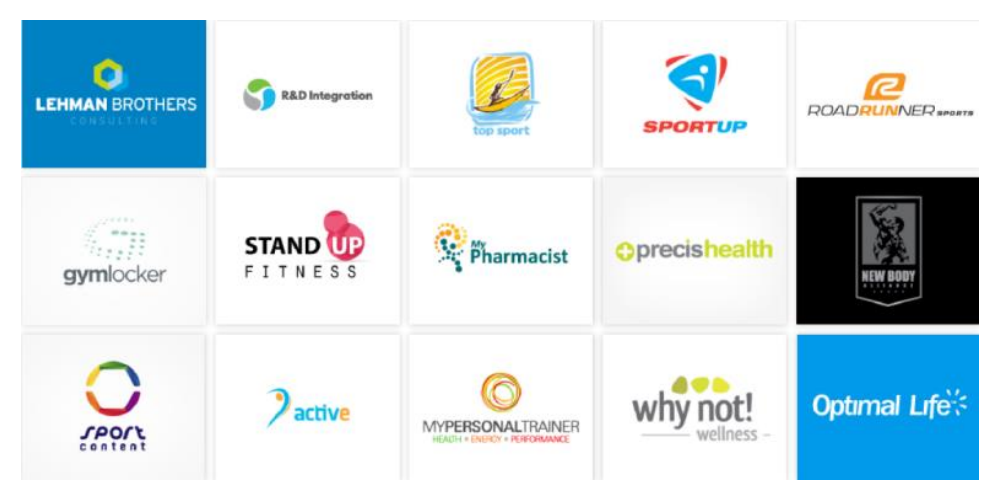

Figura 4 - Painel das identidades visuais de similares e concorrentes.

Fonte: Elaborado pelo autor, com base na pesquisa realizada.

A partir do painel semântico foi possível identificar as características visuais e os meios de transmitir os conceitos visados, fazendo uma listagem de aspectos positivos a serem abordados no desenvolvimento da identidade visual. Com essa listagem foi possível organizar uma tabela de requisitos estético-formais para auxiliar a etapa subsequente de geração das alternativas. Tendo essas características mapeadas, iniciou-se a criação dos esboços preliminares por meio da realização de grafismos manuais que representassem os conceitos definidos (Figura 5).

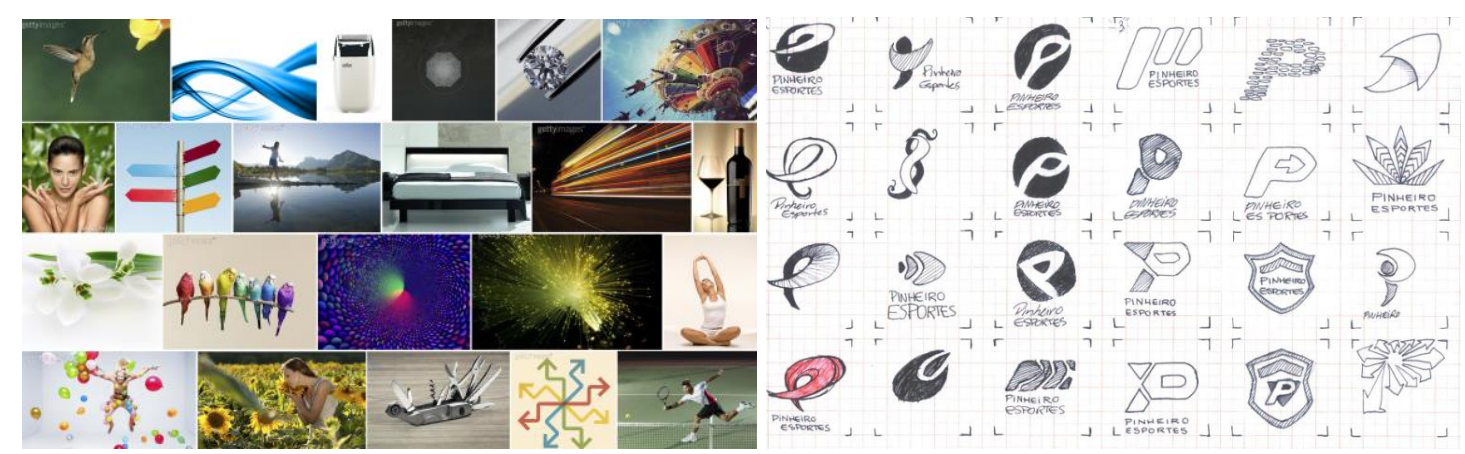

Figura 5 - Painel semântico dos conceitos e geração de alternativas.

Fonte: Elaborado pelo autor, com base na pesquisa realizada. 


\subsubsection{Etapa 4: Execução}

Com base nas propostas de esboço, foram avaliadas e transpostas para o meio digital aquelas que melhor atendiam os conceitos. Testes de aplicação e de cores foram feitos, bem como impressões para avaliação das propostas. Após os testes, duas propostas foram selecionadas para avaliação e refinamento (Figura 6).
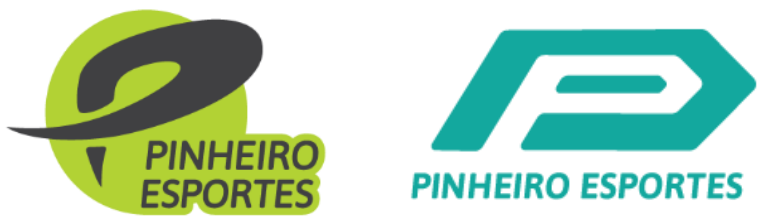

Figura 6 - Alternativas refinadas em meio digital.

Fonte: Elaborado pelo autor, com base na pesquisa realizada.

Entre as opções geradas, as alternativas na figura acima foram as que mais representavam os conceitos principais de energia e bem-estar, balanceando os demais, e apresentavam um bom potencial de síntese, legibilidade, redução da marca e impacto visual.

\subsubsection{Etapa 5: Viabilização}

Após os testes e desenvolvimento dos protótipos para a identidade visual, foi desenvolvido um questionário por meio digital (internet) para avaliação dos conceitos visados pelo projeto. 0 questionário foi aplicado com dois públicos diferentes. 0 primeiro com o público técnico da área de design (estudantes e profissionais) e o segundo com os próprios alunos da escola Pinheiro Esportes (clientes diretos). Os resultados podem ser conferidos na Figura 7. Em paralelo à pesquisa com o público, foram revistos os requisitos estético-formais do projeto, visualizando qual a alternativa que melhor contemplava os pontos elencados como satisfatórios para a marca, obtendo os seguintes resultados:

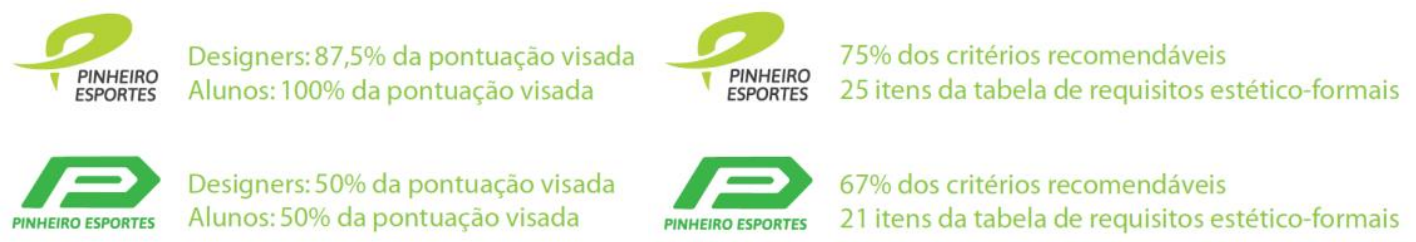

Figura 7 - Avaliação das alternativas conforme questionários e avaliação das alternativas e requisitos projetuais.

Fonte: Elaborado pelo autor, com base na pesquisa realizada.

Com as avaliações das alternativas, foram apresentados ao cliente as propostas geradas e seus resultados, bem como suas aplicações em diferentes mídias, possibilitando a definição da nova marca para a Pinheiro Esportes (Figura 8). A partir desta definição, as aplicações puderam ser finalizadas, como no caso das camisetas e assinatura de e-mail, que já estão em veiculação. 

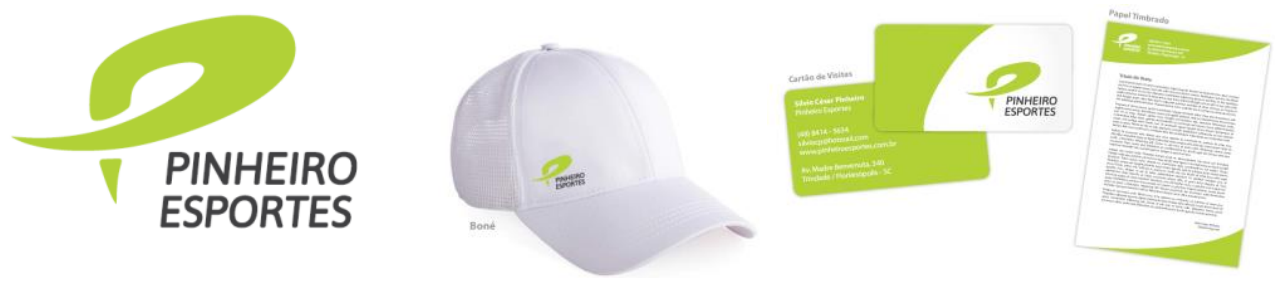

Figura 8 - Marca final e aplicações.

Fonte: Elaborado pelo autor, com base na pesquisa realizada.

\subsubsection{Etapa 6: Verificação final}

Após a apresentação e aprovação da marca e das aplicações, os materiais projetados foram enviados para produção e implementados.

\section{CONCLUSÃO}

Por meio da utilização de métodos e técnicas de design, nota-se que a possibilidade e contribuição da aplicação do design nas organizações. Assim, a gestão de design serviu para diagnosticar pontos a serem melhorados, auxiliar na clareza e definição dos objetivos organizacionais e elaboração de um plano de ações de longo prazo. Este culminou em estratégias de design e de negócios, contribuindo para a identificação e diferenciação da empresa por meio de melhorias na sua comunicação visual. Neste contexto, ressalta-se a importância e a eficiência dos processos metodológicos e técnicas utilizadas como fator determinante para o desenvolvimento do projeto e alcance dos objetivos e resultados gerados.

A partir do estudo proposto e projeto realizado, fica claro que o design vem se tornando importante para a competitividade e valorização das organizações, deixando de ser uma questão estética e tornando-se uma questão estratégica. Neste sentido, a gestão de design contribui para o alcance dos objetivos estratégicos destas organizações, no sentido de ter uma visão sistêmica das mesmas, ajudando-as a atingir seus objetivos de acordo com sua essência e contribuindo para a resolução de problemas.

Ao aplicar os estudos e métodos em casos reais, valoriza-se a produção do design e colaboração com o desenvolvimento das organizações, aliando o conhecimento teórico acadêmico com as necessidades de mercado e competitividade nas empresas.

\section{REFERÊNCIAS}

AIGA - American Institute of Graphic Arts. Design creates value for business strategy. Disponível na internet por http em:

<http://www.aiga.org/landing.aspx?pageid=10590\&id=49>. Acesso em: 11 abr. 2014.

ANDRADE, R; AMBONI, N. Teoria Geral da Administração: das origens às perspectivas contemporâneas. São Paulo: M.books, 2007.

BEST, K. Design management: managing design strategy, process and implementation. Switzerland: Ava, 2006. 
CARBELLIDO, N; MANUEL, V. Que és La qualidad? Conceptos, gurus y modelos fundamentale. México: Limusa, 2005.

DESIGN COUNCIL. What design is and why it matters. Disponível na internet por http em: <http://www.designcouncil.org.uk/about-design/Managing-Design>. Acesso em: 10 abr. 2014.

DMI. Design Management Institute. What is design management? Disponível na internet por http em:

$<$ http://www.dmi.org/dmi/html/aboutdmi/design management.htm $>$. Acesso em: 10 abr. 2014.

FERREIRA, A. Mini Aurélio: o dicionário da língua portuguesa. Curitiba: Positivo, 2004.

FERREL, O., HARTILINE, M.. Estratégia de Marketing. São Paulo: Atlas, 2000.

GILLESPIE, B. Strategic Design Management and the Role of Consulting. Disponível na internet por http em: < http://www.designingbusiness.com/BrianG SDM Rese archReport.pdf $>$. Acesso em: 12 abr. 2014

GIMENO, J. La gestión del diseño en la empresa. Madrid: McGraw_Hill, 2000.

KAPLAN, R. S.; NORTON, D. P. Mapas estratégicos: convertendo ativos intangíveis em resultados tangíveis. 5. ed. Rio de Janeiro: Elsevier, 2004.

MARTINS, R., MERINO, E.. A Gestão de design como estratégia organizacional. Londrina: Eduel/RioBooks, 2011.

MERINO, E. Gestão de design: inovação e integração. Revista ABCDesign, 2002.

MERINO, Giselle Schmidt Alves Díaz. A contribuição da gestão de design em grupos produtivos de pequeno porte no setor da maricultura: o caso AMPROSUL. 2010. $184 \mathrm{f}$. Dissertação (Mestrado) - Universidade Federal de Santa Catarina, Programa de PósGraduação em Design e Expressão Gráfica.

MERINO, Giselle Schmidt Alves Díaz. Metodologia para a prática projetual do Design com ênfase no Design Universal. 2013. 130 f. Qualificação Tese (Doutorado) Universidade Federal de Santa Catarina, Curso de Programa de Pós Graduação em Engenharia de Produção.

MOZOTA, B. Gestão do Design: usando o design para construir valor de marca e inovação corporativa. Porto Alegre: Bookman, 2011.

PINHEIRO ESPORTES. Disponível na internet por http em:

<http://pilatespinheiro.blogspot.com.br/>. Acesso em: 11 abr. 2014.

SOUZA, S. Metodologia para desenvolvimento e implantação de sistemas de gestão da qualidade em empresas construtoras de pequeno e médio porte. PhD. Escola Politécnica. Universidade de São Paulo, 1997.

TEIXEIRA, J. Identificação e Proteção: O Design Valorizando Grupos Produtivos de Pequeno Porte. Mestrado. Universidade Federal de Santa Catarina, 2011.

WOLF, Brigitte. 0 design management como fator de sucesso comercial. Florianópolis/SC: IEL - Abipti - Programa Catarinense de Design, 1998. 